\title{
MENTAL HEALTH PROBLEMS AMONG SCHOOL GOING ADOLESCENTS IN INDIA: A LITERATURE REVIEW
}

\author{
Ainamlin Dkhar* \\ "Research Scholar, \\ Department of Social Work, \\ School of Social Sciences, \\ Mizoram University, \\ Aizawl, Mizoram, \\ India
}

\author{
Grace Lalhlupuii Sailo** \\ ***Assistant Professor, \\ Department of Social Work, \\ School of Social Sciences, \\ Mizoram University, \\ Aizawl, Mizoram, \\ India
}

Article DOI URL: https://doi.org/10.36713/epra6667

DOI NO: 10.36713/epra6667

\begin{abstract}
School going adolescents are in a transition period that bridges childhood and adulthood, during which major physical, cognitive, and psychological changes occur. Today's youngadolescents deal with issues related to suicide; and many other social, emotional, physical and psychological issues. These internal stresses and social expectations lead to moments of ambiguity, self-doubts and disappointment in the adolescents. It is in these situations that the young person takes risks and involves in risk taking behaviors. The present review is focused on mental health problems of school going adolescents in India based on pertinent studies from different online search engines, journals and articles of the past years. The reviews illustrationthe high and increasing prevalence of Mental Health problems among school going adolescents and the need for school based Mental Health services in every school in the country.

KEY WORDS: School-going, adolescent, Mental Health, problems, Review, India.
\end{abstract}

\section{INTRODUCTION}

Indian youth represent a significant proportion of the worldwide population. As per census 2011, youth (15-24 years) in India constitute one-fifth (19.1\%) of India's total population. India is expected to have $34.33 \%$ share of youth in total population by $2020^{1}$. Mental health is one of the most important aspects of development among school going adolescents yet the most neglected. India, a developing country needs much improvement of its mental health care services, especially among school going adolescents.

\section{MENTAL HEALTH PROBLEMS AMONG SCHOOL GOING ADOLESCENTS IN INDIA}

The review is based on the secondary data from online resources such as PubMed, Google scholar, Psych- info journals. Several studies from the past 10 years were reviewed based on the Mental Health aspects of school going adolescents and terms like Health and Mental health problems, prevalence, challenges, psychosocial, behavioral and emotional problems, suicide, psychiatric disorders were used in the search engine. The following are the major findings found from the review. 
A number of scales were focused on mental health assessment of school going adolescents such as SDQ questionnaires, Youth Self Report (YSR) questionnaires, ICD-10 criteria tools, Child behavior checklist, PSC-Y questionnaires, Beck Depression Inventory, GHQ-12. SDQ questionnaires and Youth self-reports, are the most common used tools to understand the Mental Health problems of School going Adolescents. The mental health problems found frequently among school going adolescents are depression and stress, substance abuse, educational difficulties, anxiety, conduct disorders, emotional problems, behavioral problems, hyperactivity; and suicidal tendencies.

There are widevariations in the Mental Health rates of adolescents from $0.48 \%$ to $29.40 \%{ }^{2}$. A study conducted in Dehradun showed the overall prevalence of psychosocial problem to be $40.5 \%$ with $34.5 \%$ in rural areas\& $46.5 \%$ in urban areas. Depression was the most common psychosocial problem, among adolescent females followed by educational difficulties. Among adolescent males, substance abuse was the most common psychosocial problem followed by educational difficulties and anxiety ${ }^{3}$.A school based cross-sectional study conducted to assess behavioral and emotional problems of school going adolescents in Chandigarh, revealed that the prevalence of behavioral and emotional problems in adolescents was found to be $30 \% 4$. A comparison of urban Indian adolescents among working and non-working mothers conducted in Chennai revealed that students had conduct problem, peer problem, hyperactivity problem and pro-social problem 5 . Another study intended to understand the mental health problems among adolescents and its psychological correlates, revealed that attention deficit disorder, internalizing problems, externalizing problems and suicidal proneness are present among school adolescents with $14 \%$ overall prevalence of Mental Health problems ${ }^{6}$.

The domain wise finding shows more emotionalproblems among females and more conduct problems among male students ${ }^{7}$. No significant difference in prevalence rate was observed between males and females, or between children belonging to joint and nuclear families ${ }^{8}$. Also, there was no significant difference in prevalence of mental health issues between middle class urban and rural children'. Sibnath Deb et al (2010) examined, adolescent anxiety among high school students in India, wherein, results show that anxiety was prevalent in the sample with a fifth $(20.1 \%)$ of boys and more than a sixth $(17.9 \%)$ of girls found to be suffering from high anxiety ${ }^{10}$. Jayant and Thirunavukarasu (2015) conducted a study on the prevalence of depression among school going adolescents in South India revealing $45.7 \%$ of adolescents with a moderate degree of depression with only $9.3 \%$ reporting minimal depression ${ }^{11}$.A study by Mohammad (2017) shows that the rate of drug abuse is very high among adolescent students and there are many ill effects of addiction on their psychological conditions ${ }^{12}$. A strong relationship has been found between emotional and behavioral problems among adolescents ${ }^{13}$.

The above reviews found a high and increasing prevalence of Mental Health problems among school going adolescents and suggested that school based Mental Health services should be implemented in every school in the country.

\section{BARRIERS IN ACCESSING MENTAL HEALTH CARE SERVICES}

The current treatment gap for mental problems is a result of inadequate coverage of mental health services as well as under-utilization of mental health services by the community. Additionally, the quality of the care delivered in some settings is meager and inadequate. Logistic barriers, financials barriers, child characteristics, and parental characteristics and beliefs are also some of the barriers in accessing Mental Health care services. Widespread taboos and social stigma towards, and discrimination against, people with mental disorders is an important barrier to service utilization. It contributes to delays in seeking care, impedes timely diagnosis and treatment for mental disorders, serves as an impediment to recovery and rehabilitation, and ultimately reduces the opportunity for fuller participation in life ${ }^{14}$. It is important for professionals to understand the barriers which parents and children face in accessing services in order to increase the accessibility of children's mental health care amenities.

\section{THE NEED TO PROMOTE AND PREVENT MENTAL HEALTH AMONG SCHOOL GOING ADOLESCENTS}

Based on findings, several studies have suggested suitable interventions that would aid-in the adolescent students, to cope with the challenges of their life stages and the demands of everyday life. Adolescents are involving in various harmful, unsafe and unhealthy behaviors which suggest that needsbased educational programmes should be made mandatory for adolescents in schools and colleges focusing on awareness, situational effects, short term and long term consequences on health and well-being and peer culture. These interventions need to be interspersed with a preventive focus on teaching skills to meet challenges, to exercise self-control, establish 
meaningful goals, make healthy life choices and maintain healthy relationships ${ }^{15}$.Integrating Mental Health into general health care, effective mass media coverage, networking between mental healthprofessionals and other health professionals, community-based health services and involvement of professionals from the education sector are some of the vivacious suggestions given ${ }^{16}$.

School based consultation services for child Mental Health are not employed either in the developing or the developed world to the degree possible. Further, in developing countries the potential of having professionals trained in social work, psychology, education and other fields is not utilized for Mental Health care of children and adolescents because of lack of supplemental training in child Mental Health. Considering that school going adolescents represent a large proportion of the country's population, there is an urgent need to develop Mental Health resources to promote mental health services and prevent mental health issues among school going adolescents .There is an immense need of timely intervention to preserve the psychosocial health of this apparently healthy group.

\section{CONCLUSION}

Mental Health problems are common among the adolescent population in India and early detection and effective intervention will benefit in the wholesome development of the future citizens of our country. There is a high prevalence of mental health problems among school going adolescents, which shows that there is a need to develop collaborations among mental health professionals, psychologist, social workers, school authorities, pedagogical strategic think tanks, welfare administers, teachers and parents in preventing mental illness as well as with social policy analysts in developing, implementing, and evaluating the interventions.

\section{REFERENCES}

1. GOI. (2011).Census of India provisional population Totals, paper 2, volume 1 of 2011. Rural-Urban distribution, Delhi; Office of the Registrar General \& census commissioner Ministry of Home Affairs, GOI

2. Malhotra, S., \&Patra, B. N. (2014). Prevalence of Child and Adolescent Psychiatric Disorders in India: A Systematic Review and Meta-analysis. Child and Adolescent Psychiatry and Mental Health, 8:22, 1-9, available from www.capmh.com/content /8/1/22.

3. Sharma, A., Gupta, S. K., Luthra, M., \& Mishra, P. (2014). Psychological Problems of Adolescents: Influence of Age, Sex and Area of Residence.
Journal of Advance Researches in Biological Science, 6(2), 130-3, available from www.ejmanager.com/mnstemps/86/861415166938.pdf.

4. Pastor, N. P., Rouben, C. A., \& Duran, C. R. (2012). Identifying Emotional \&Behavioural Problems in Children Aged 4-17 Years: United States, 2001-2007. National Health Statistics Report, 48, 1-17.

5. Srinivasan, P., \& Caroline, P. K. (2014). A Comparison of Mental Health of Urban Indian Adolescents among Working and Nonworking Mothers. Annals of Community Health, 2(2), 39-43, available from www.annalsofcommunityhealth.in/ojs/index.php/AO CH/article/.../62.

6. Arumugam, B., Rajendran, S., \&Nagalingam, $S$. (2013). Mental Health Problems among Adolescents and its Psychological Correlates. Indian Journal of Research, 2(3), 284 - 287.

7. Reddy, B.K., Biswas, A., \&Rao, H. (2011). Assessment of Mental Health of Indian Adolescents Studying in Urban Schools. Malaysian Journal of Pediatrics and Child Health Online early-05-17-1.

8. Bansal, P. D., \& Barman, R. (2011). Psychopathology of school going children in the age group of 10-15 years. International Journal of Applied and Basic Medical Research, 1 (1), 43 47.

9. Sarda, R., Kimmatkar, N., Hemnani, J. T., Hemnani, T. J., Mishra, P., \& Jain, S. K. (2013). Prevalence of Psychiatric Disorders in Western U. P. Region - A School Based Study. International Journal of Scientific Study, 1(3), 7076, available fromhttp://www.ijsssn.com/uploads/2/0/1/5/20153321/original_article_ 9.pdf.

10. Sibnath, D.,Pooja, C., Kerryann.,W. (2010). Anxiety among high school students in India: Comparison across gender, school type, social strata and perceptions of quality time with parents. Australian Journal of Educational \& Developmental Psychology. Vol 10, pp 18-3.

11. Jayanthi, P., \&Thirunavukarasu, M. (2015). Prevalence of Depression among school going adolescents in South India. International Journal of Pharmaceutical and Clinical Research, Vol. 7 (1), 61-63.

12. Mohammad, A. (2017). Factors related with drug/alcohol addictions among school going students in Pune, India. The International Journal of Indian Psychology, Vol 4 (3), 151-158.

13. Rama Rao, K. T., \&Raju, M.V.R. (2012). Early adolescent: emotional and behavioral problems. Journal of the International of the Indian Academy of Applied Psychology, Vol. 38 (1), 34-39.

14. Shidhayea.,R, \& Kermode., M. (2013). Stigma and discrimination as a barrier to mental health service 
utilization in India. Int Health 5: 6-8 doi:10.1093/inthealth/ihs01.

15. De Souza, J.F. (2017). Adolescents and risky behaviors. Proceedings of the (ICLSE-2017): International Conference on Life Skills Education Life Skills for Achieving Sustainable Development Goals 2030, (pp.262-267). Excel India Publisher: New Delhi.

16. Kaur, S., Thapar, S. K., \&Shandilya, V. (2015). The Prevalence of Psychitric Morbidity among School Children. International Journal of Medical and Dental Science, 4(2), 834-41, available from http://ijmds.org/wp-content/uploads/2015/06/834841-Ju-RA-school.pdf. 